Keywords geology; site investigation; tunnels \& tunnelling
Joe Lenham

MSc, PhD, FGS, CGeol

is a water management consultant at Entec UK and formerly senior geophysicist at Reynolds Geo-Sciences Ltd, Mold, UK

Vaughan Mever BE(Hons), PhD, CPEng, IPE(NZ), MIPENZ

is a senior geotechnical engineer at Geotechnical Consulting Group, London, UK

Helen Edmonds MSc, DIC, FGS

is an associate director at Geotechnical Consulting Group, London, UK David Harris MSc, DIC, CEng, MICE

is a director at Geotechnical Consulting Group, London, UK

\section{Rory Mortimore}

BSE(Hons), PhD, CGeol, FGS

is a professor of engineering geology at Brighton University, UK

\section{John Reynolds BSc(Hons), PhD, CGeol,
EurGeol, FGS, FRAS, FConsE \\ is managing director of Reynolds Geo-Sciences Ltd, Mold, UK}

Mike Black MSc, CGeol, FGS

is the senior geotechnical design manager at Cross London Rail Links Ltd, London, UK

\title{
What lies beneath: surveying the Thames at Woolwich
}

\author{
Line I of the Crossrail project is planned to cross the River \\ Thames via twin tunnels at Woolwich in east London. This \\ paper reports on the fascinating investigation into the \\ riverbed of Woolwich Reach, involving integration of a wide \\ range of data from historical, geophysical and borehole \\ sources. It illustrates how combining detailed desk studies and \\ focused borehole investigations with over-water seismic, \\ sonar and magnetic gradiometer surveys can assist civil \\ engineers in the design of major structures within historic \\ urban and tidal river environments.
}

A UK Government select committee is currently considering the Bill for the Crossrail project following its successful second reading in July 2005. If its gets the green light, work on the project could start in 2007. Line 1 is planned to link east and west London, crossing the River Thames via proposed twin tunnels at Woolwich.

Designing the tunnels required detailed knowledge of the bathymetry and geological structure of this historic riverbed, so a comprehensive desk study coupled with over-water geophysical and intrusive ground investigations were undertaken during the winter of $2003 / 2004$. This paper summarises the results from these investigations and highlights the benefits to civil engineers of integrating data from different investigation techniques.

\section{Crossrail Line I}

The Crossrail project has a rather protracted history. Following the Central London Rail Study of 1989, ${ }^{1}$ work was started by London Transport and British Rail to develop a new east-west rail link across London. However, in 1994 the project was shelved in the wake of the recession and the associated reduction in passenger journeys into and through the capital.

In 2000, with both the London Underground and national rail networks suffering record levels of congestion and reduced service reliability, the government asked the Strategic Rail Authority (SRA) to study the requirements for extra passenger capacity to and through London. The resulting London East-West Study ${ }^{2}$ recommended that both the east-west and Hackney-southwest routes, developed under the previous Crossrail project, be resurrected and schemes developed to construct them. To achieve this aim, a 50/50 joint venture company (Cross London Rail Links Ltd) was formed by Transport for London (TfL) and the SRA to define, develop and promote these two new railways.

Crossrail Line 1 is the former east-west route, the heart of which is the construction of a new tunnelled alignment across London, with new stations at Paddington, Bond Street, Tottenham Court Road, 


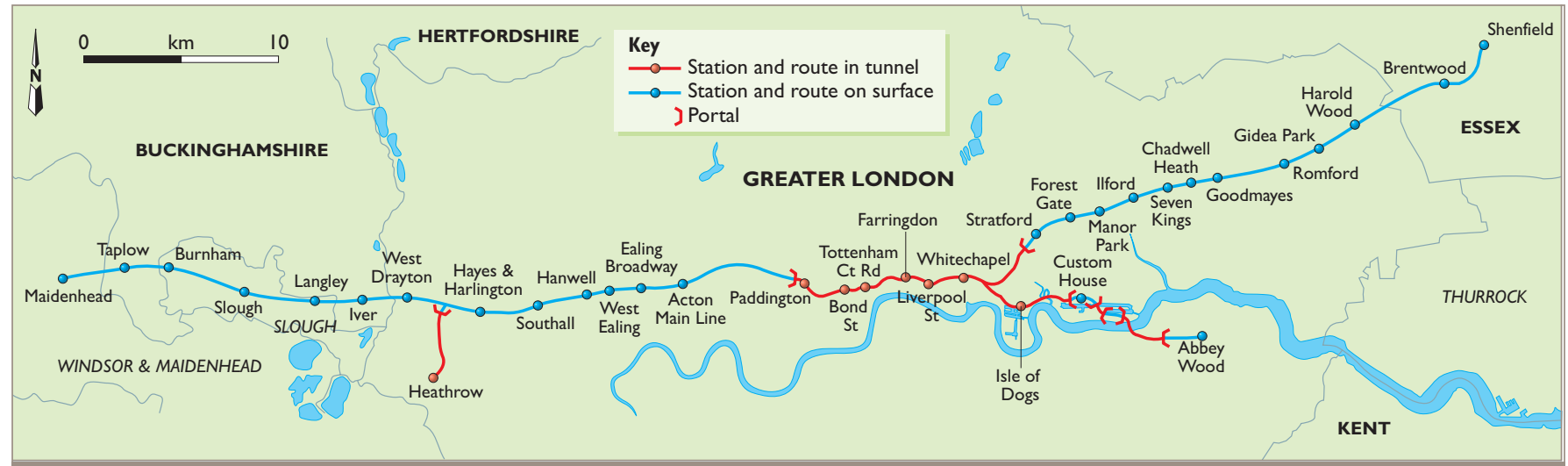

Fig. 1. Proposed route of Crossrail Line 1, showing the planned Thames erossing on the branch to Abbey Wood

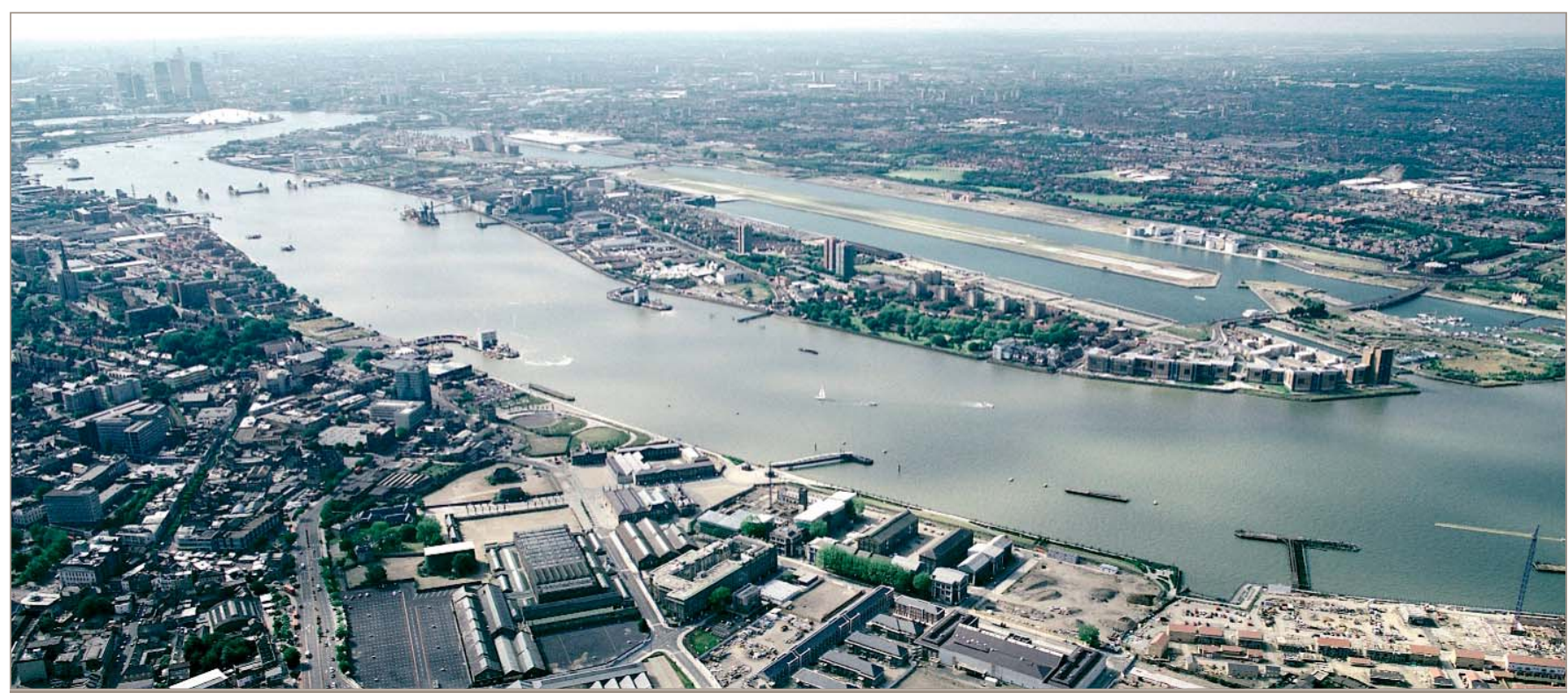

Fig. 2. Aerial view of Woolwich Reach looking north-west, showing the Royal Arsenal development in the foreground and London City Airport to the north (courtesy Berkeley Homes)

Farringdon, Liverpool Street, Whitechapel and the Isle of Dogs, as well as an option to serve Heathrow Airport (Fig. 1).

\section{Woolwich Reach}

Woolwich Reach is located immediately east of the Thames Barrier (Figs 2 and 3) and, as with every other section of the River Thames running through central London, is steeped in history. In particular, the Woolwich area was renowned for its chemical, engineering and food-processing industries. With the opening of the Royal Victoria Dock in 1855 and the Royal Albert Dock in 1880, Silvertown-situated on the northern side of the river-

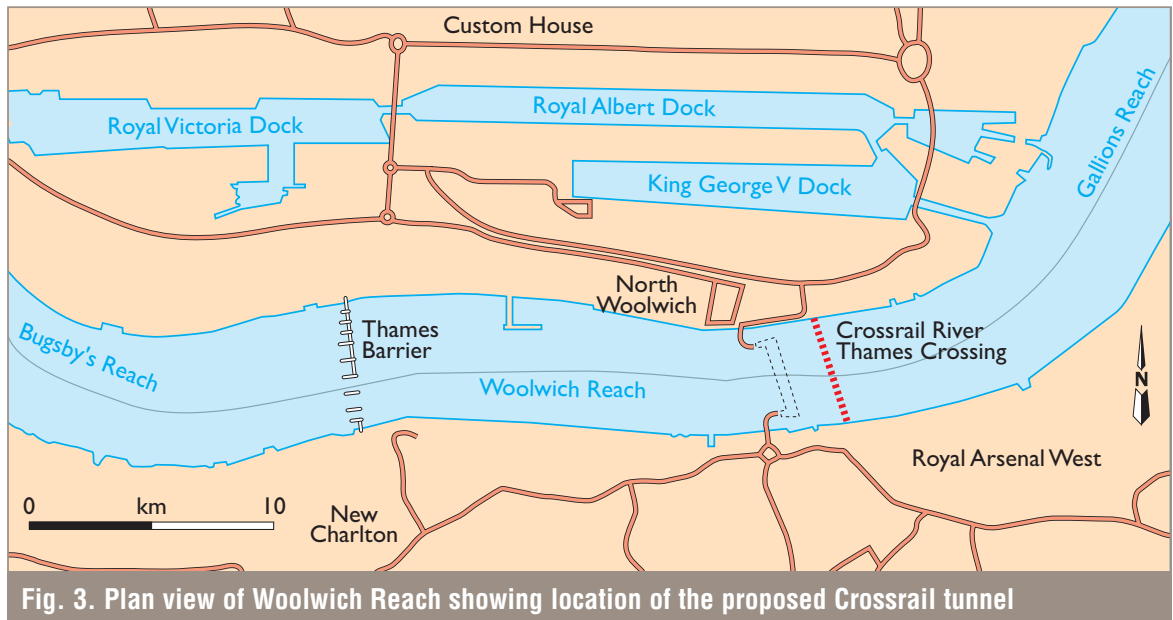


became the largest manufacturing centre in southern England. Local industry relied heavily on the Royal Docks, through which raw materials were imported from all over the world.

Given the economic importance of this section of the river, it comes as little surprise that in the early part of the last century, around 1910, the Port of London embarked on a capital dredging campaign to create a deepwater channel in the River Thames. The last section to be dredged, probably in the early 1920s, was that from Gallions Reach to Lower Pool. Since then it is understood there has been no significant dredging in Woolwich Reach, though there may have been some maintenance dredging associated with the Royal Arsenal, the Woolwich Ferry and the Tate \& Lyle factory.

During World War I, but more particularly during World War II, the docks and munitions factories in the Woolwich area were key targets for aerial bombardment. The resulting devastation, coupled with technological changes such as the containerisation of shipping, led to the closure or relocation of many long-established industries. The docks, which had provided the base for much of the area's economic

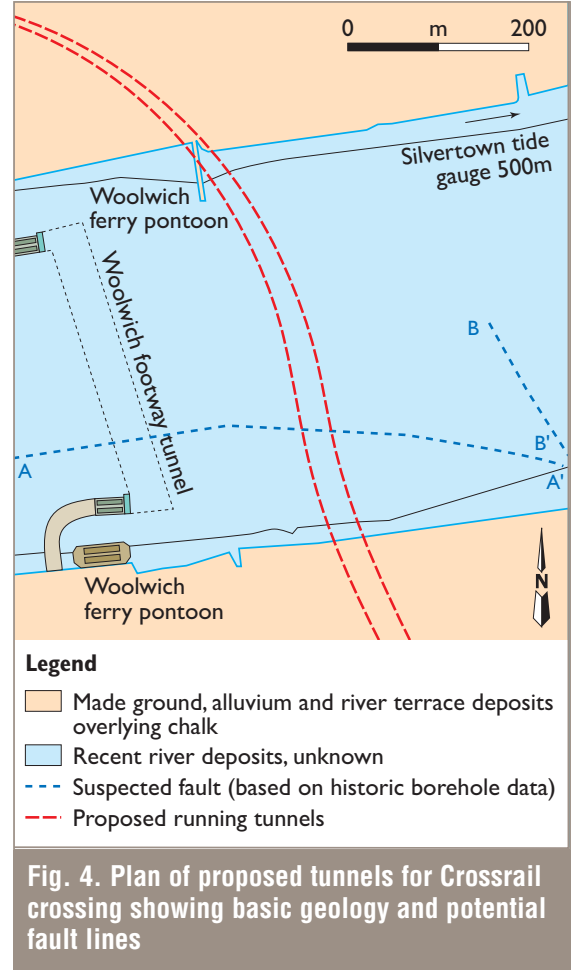

and community activity, closed in 1981 .

A ferry service has operated across the river at Woolwich since the fourteenth century. The present free ferry service links the London boroughs of Greenwich and Newham as well as the inner-London North Circular and South Circular orbital routes. Pedestrians can use the ferry along with the nearby Woolwich footway tunnel.

At the location of the proposed Crossrail Line 1 crossing, the River Thames is approximately $400 \mathrm{~m}$ wide and exhibits a tidal variation in the order of 5-7 m.

Woolwich Reach is understood to be at the upper limit of the seasonal mud reaches of the Thames estuary. As a consequence, local bed level variations of up to $1 \mathrm{~m}$ between summer and winter can occur.

\section{Desk study information}

Published geological information on Woolwich Reach is scant, although the British Geological Survey (BGS) has mapped the regional geology of the Dartford area $^{3}$ and published an associated memoir. ${ }^{4}$ A recent bathymetric plan of Woolwich Reach has been produced by the Port of London Authority ${ }^{5}$ (PLA) and construction of the existing 1912 Woolwich footway tunnel has been described. , $^{7}$ Copies of construction drawings for the footway tunnel were also obtained from the London Borough of Greenwich along with historic bathymetric soundings at the location of the footway tunnel taken during
1909, 1931-1932 and 1971.

The desk study carried out prior to fieldwork operations amassed and correlated borehole information for the Woolwich area dating from the nineteenth century to recent times. Virtually all of these boreholes were sunk on land. The lack of a reference datum and changes in ground levels presented some difficulties to the correlation of the older borehole records.

Nonetheless, a shallow geological model of this area was constructed indicating that on the riverbanks made ground overlies alluvium and river terrace deposits (sands and gravels) as shown in Figs 4 and 5 .

From the accumulated desk study information, the Crossrail running tunnels at Woolwich are anticipated to be constructed primarily through chalk, though overlying river terrace deposits, alluvium and made ground can be expected as the tunnels rise towards the surface on the northern and southern shores. Several suspected faults have been inferred from the chalk-head levels identified from the historic borehole records and the approximate positions of the faults are indicated on Fig. 4.

The composite geological section presented in Fig. 5 shows the interpreted riverbed structure close to the position of the Woolwich footway tunnel, approximately $150 \mathrm{~m}$ west of the proposed Crossrail running tunnels. Chalk bedrock lies at around -11 m OD (Ordinance Datum) below the northern shore and around $-3 \mathrm{~m}$ OD below the southern

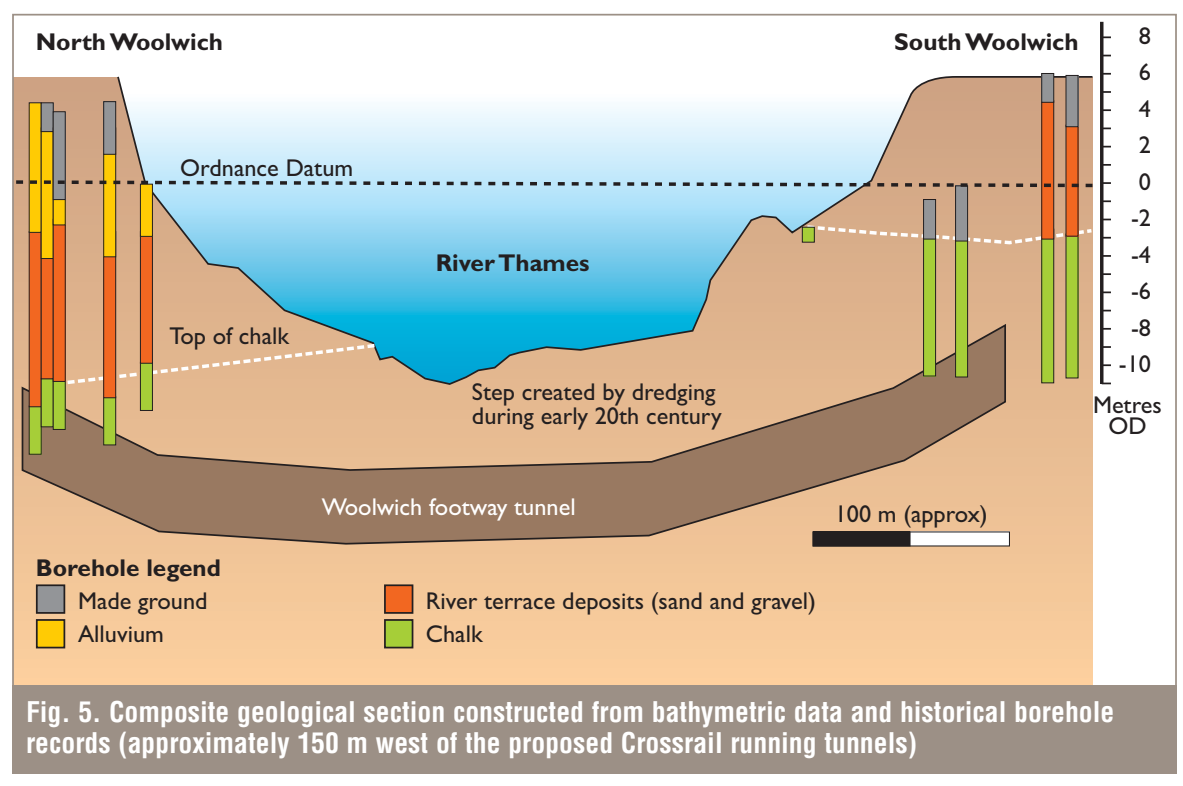


shore. Records from construction of the footway tunnel ${ }^{6,7}$ and ferry pontoons show riverbed chalk exposures adjacent to the present southern ferry pontoon. A further concern identified during the desk study was the possibility of encountering unexploded ordnance (UXO) resulting from bombing of this area during both world wars.

\section{Over-water geophysical surveys}

Over-water geophysical surveys were carried out using the $M V$ Meridian during January 2004, two months prior to the intrusive ground investigation (Fig. 6). The purpose of these surveys was to

determine accurately the bathymetry of the riverbed in the vicinity of the proposed river crossing for Crossrail Line 1

- identify any services or other tunnels beneath the river which may present a hazard to the tunnels or be affected by their construction

- identify near-surface metallic objects, including any UXO, which could present a hazard to the intrusive ground investigation and/or tunnelling operations

- investigate the subsurface geology of the area and identify any significant geological features (e.g. changes in stratigraphy and faults).

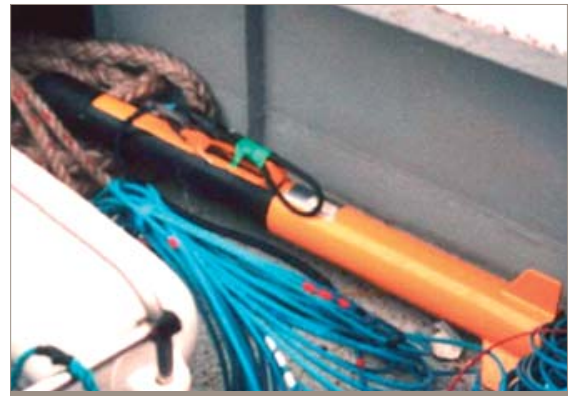

Fig. 7. Side-scan sonar tow fish used to generate a horizontal view of riverbed features and texture, enabling identification of upstanding objects

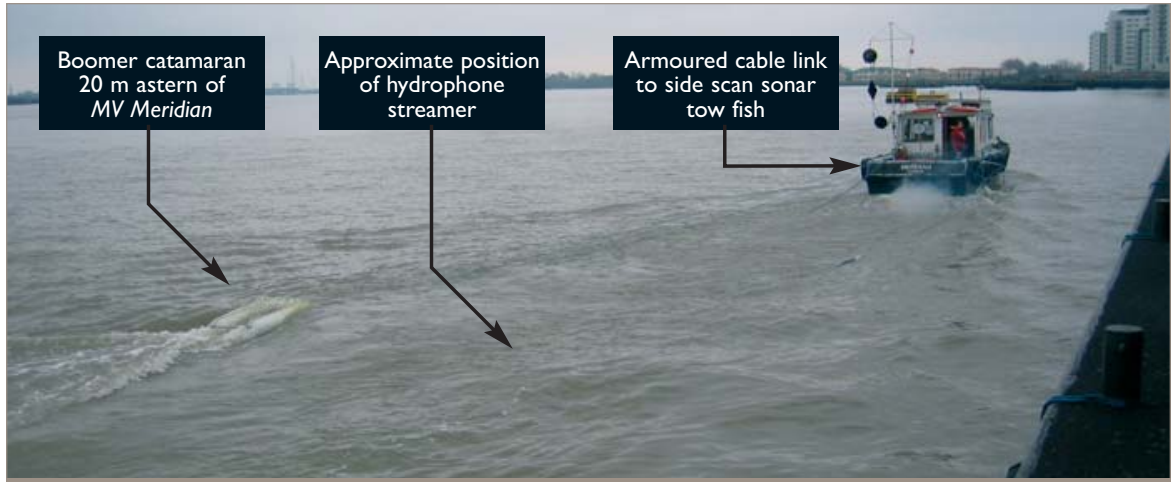

Fig. 6. MV Meridian undertaking the over-water geophysical survey in January 2004

The geophysical surveys were expected to assist with the identification of suitable borehole locations and, when coupled with borehole data, provide increased confidence in the ground conditions over a greater coverage area.

Bathymetric data were acquired at all stages of the survey operations using a Knudson 320 dual-frequency echosounder mounted on the hull of the survey vessel. Acoustic transmission velocities for the river water were calibrated from a bar check test before and after the survey. The measurement precision for all recorded bathymetric data was $\pm 24 \mathrm{~mm}$.

To assess the distribution of ferrous material at or close to riverbed level, the site was surveyed using side-scan sonar (Fig. 7) and a near-bottom towed magnetic gradiometer (Fig. 8). Side-scan sonar generates a horizontal view of riverbed

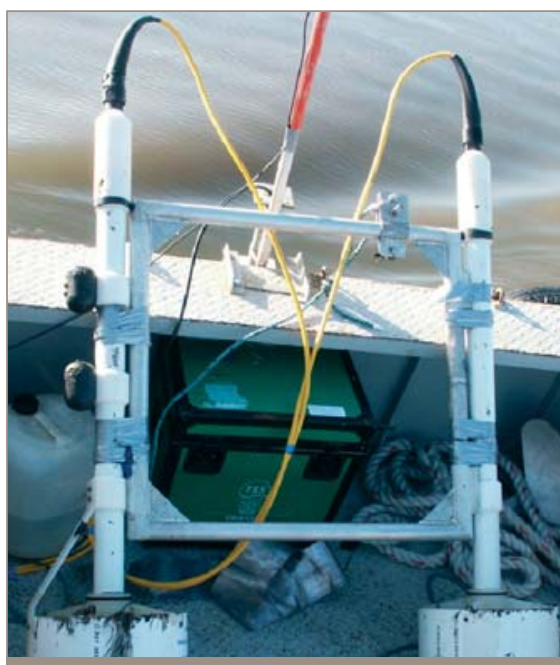

Fig. 8. Near-bottom towed magnetic gradiometer used to assess distribution of ferrous material at or close to the riverbed features and texture, enabling identification of any upstanding objects. ${ }^{8,9}$ The magnetic technique responds to local changes in the earth's magnetic field caused by nearby iron-rich material. The size and strength of any field anomaly is proportionate to the size, depth and magnetic susceptibility of the causative body. ${ }^{10}$ The survey comprised lines at $5 \mathrm{~m}$ intervals orientated parallel to the river and extending across the entire width of the river. Bathymetric data were also acquired during the magnetic gradiometer survey.

Geological structure was investigated using a high-resolution seismic sub-bottom profiling 'boomer' device (Fig. 9).$^{11}$ Data were acquired with an Applied Acoustics AA200 boomer system allied to a Codaoctopus DA200 digital recording system that facilitated post-survey processing and interpretation. The survey comprised

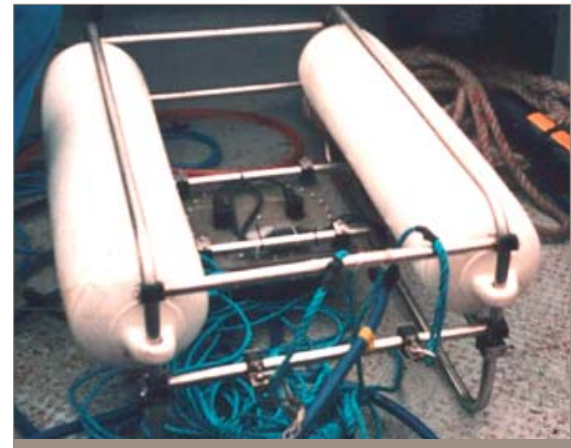

Fig. 9. Seismic boomer catamaran used to investigate geological structure beneath the riverbed 


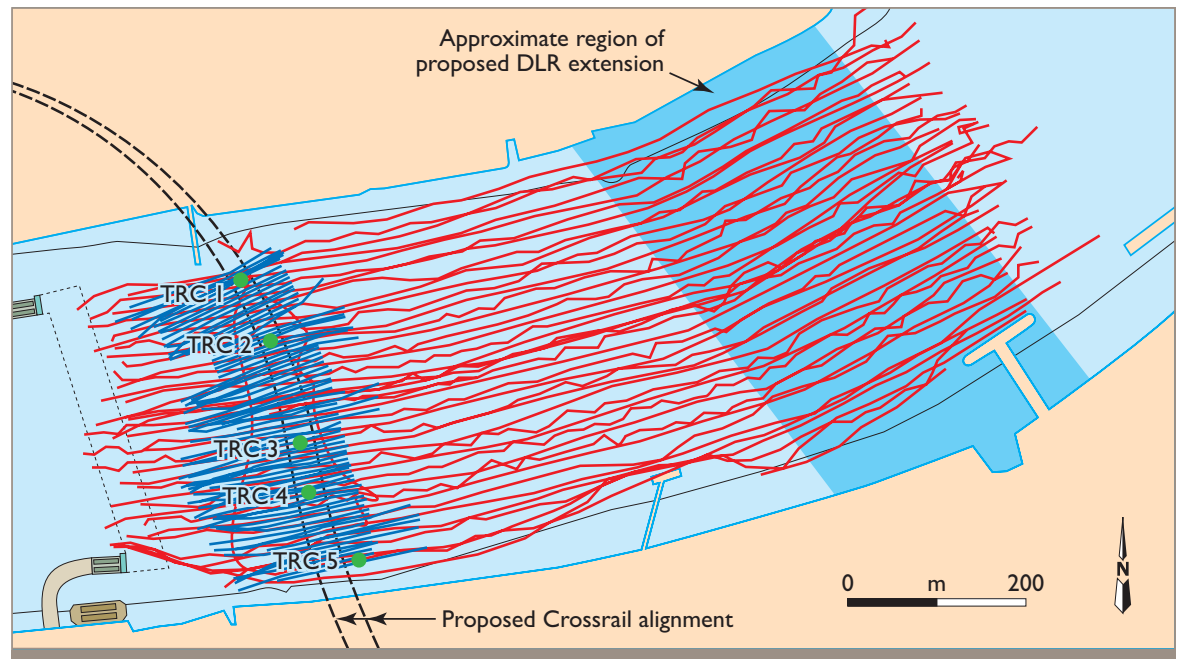

Fig. 10. Geophysical survey coverage-red lines are boomer and sidescan sonar tracks, blue lines are magnetometer tracks, green dots are borehole positions proposed tunnel invert.

Standard penetration tests (SPTs) were performed at approximately $3 \mathrm{~m}$ intervals in each borehole, with single-packer permeability tests also carried out within the tunnel horizon. A suite of down-hole geophysical tests, incorporating XY calliper, acoustic televiewer, natural gamma, conductivity, resistivity and temperature was performed in each borehole on completion of coring. Each borehole was subsequently backfilled with cement-bentonite grout in accordance with Environment Agency requirements.

For laboratory geotechnical testing purposes, U100 and bulk disturbed samples were taken from the superficial deposits and sub-samples were taken from the chalk core. Samples were also taken for chemical testing from both the superficial soils and from the chalk core within the tunnel horizon.

\section{Bathymetric and magnetic results}

Bathymetric and magnetic gradient data are shown in Figs 11 and 12. Site bathymetry comprised a channel of flat-bottomed profile and a general elevation of $-10 \mathrm{~m}$ OD. Deeper water (around -13 m OD) toward the eastern end of the survey area is inferred to be the result of dredging for entrance into King George V Dock.

From historic engineering drawings for the Woolwich footway tunnel dating from 1909 and 1933, it is understood that approval for a $183 \mathrm{~m}$ wide deep-water channel was given by the PLA in February 1912. Bathymetric data from 1931-1932 and 1972 suggest this deepwater channel was constructed sometime between 1912 and 1931. This is reinforced by the approximately $200 \mathrm{~m}$ wide, relatively flat channel identified in the current bathymetry.

Interpretation of data from the magnetic gradiometer survey identified several unknown metallic anomalies following elimination of targets caused by known structures such as pier supports, buoys and navigation lights. Superimposing magnetic data over bathymetry indicated that the majority of these anomalies formed linear alignments on the riverbed. These were interpreted as debris from point sources, distributed by the action of tides and river currents. One anomaly detected 
high on the southern slope of the channel correlated with side-scan sonar sonographs and seismic data and was identified as the terminus of water intake pipes for the former Woolwich power station, now the Waterfront Leisure Centre car park.

Linear anomalies identified on the channel bed were treated as potential UXO. The positions of five proposed boreholes forming the intrusive ground investigation were compared with these features and altered as necessary to minimise the perceived risk of striking ordnance or other metallic debris.

\section{Borehole results}

The borehole investigations encountered varying thicknesses of made ground, alluvium and river terrace deposits overlying chalk. Chalk-head levels were observed to vary between approximately -6 and $-17 \mathrm{~m}$ $\mathrm{OD}$, with the higher levels on the southern side of the river. These results are in good agreement with the desk study information summarised previously.

Of particular interest was borehole TRC 2 which proved $8 \mathrm{~m}$ of alluvium and river terrace deposits overlying the chalk. This increased depth of alluvial sediments is considered to be associated with an erosion or dissolution feature in the chalk.

The chalk cores recovered from the rotary boreholes were logged by Professor Rory Mortimore from the University of Brighton. ${ }^{12}$ This logging provided detailed stratigraphy, geological structure and engineering-grade interpretations of the chalk. Based on a combination of lithological features and fossils obtained from the cores, the stratigraphic position of the boreholes was identified indicating that they were all in the lower and middle part of the Seaford Chalk Formation. ${ }^{13}$ Marker beds, particularly the Belle Tout Marls and shelly horizons with particular types of inoceramid bivalve made it possible to construct a correlation framework for the chalk cores. The resulting logs are shown in Fig. 13.

The chalk was typically described as being weak, medium-density, white or offwhite chalk, with flints encountered at various depths. The uppermost 2-9 $\mathrm{m}$ of the chalk was recovered as silt-sized comminuted material with a variable proportion of larger-sized fragments.

Interpretation of the engineering grade

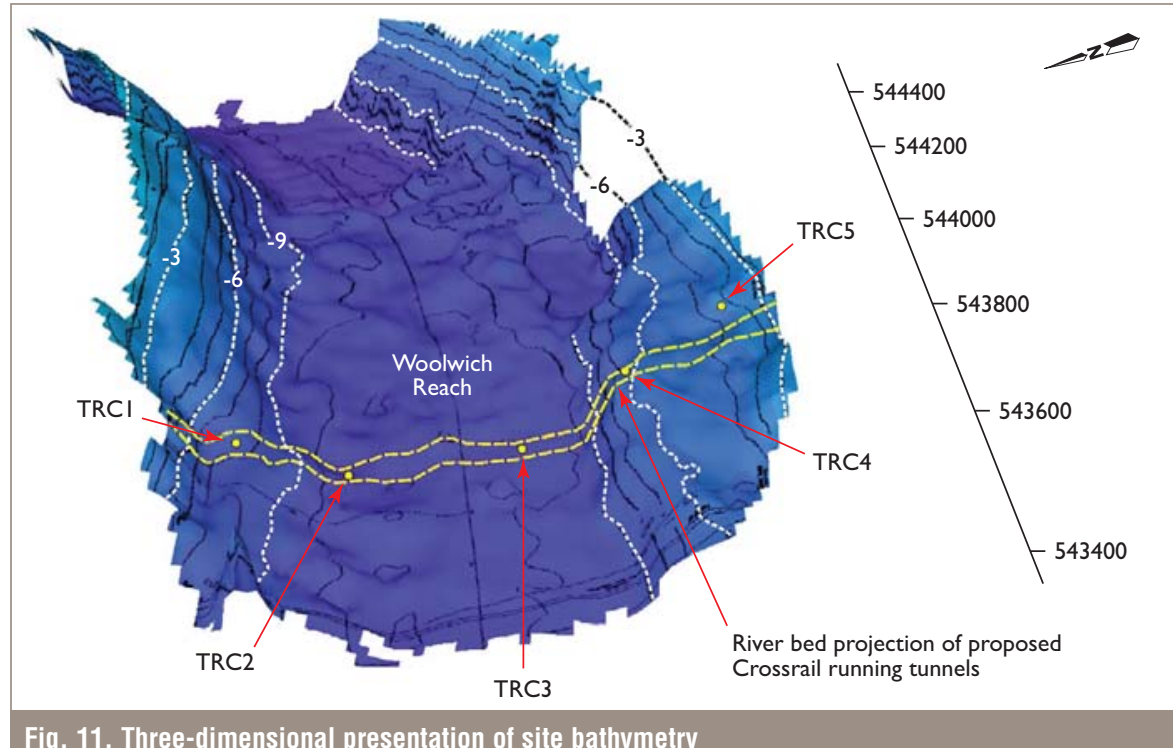

Fig. 11. Three-dimensional presentation of site bathymetry

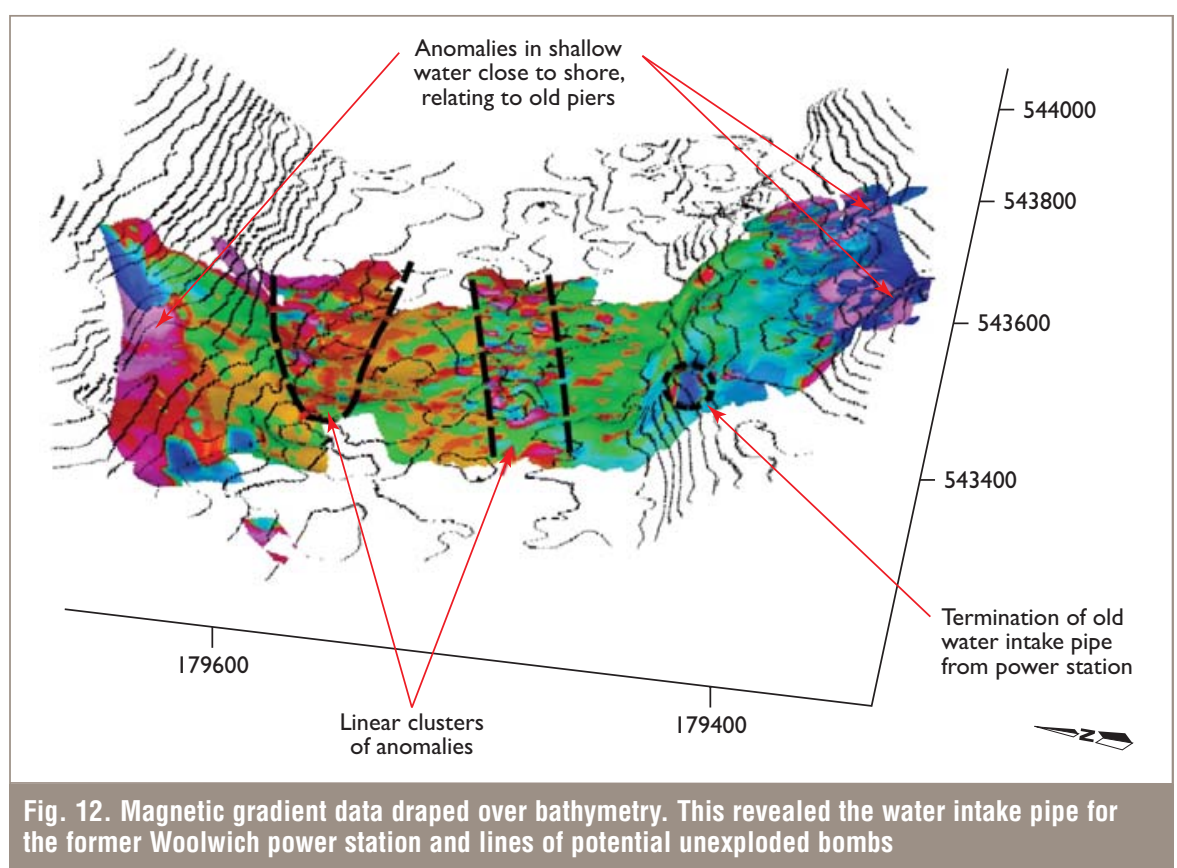

of such material is particularly difficult, or even impossible. In places, by matching up pieces of core and recording the degree of mineral staining on fracture surfaces (iron oxides and/or clay minerals), an estimate of fracture aperture was made. This degree of staining or fill was used, where appropriate, to give a CIRIA ${ }^{13}$ grading, typically $\mathrm{C} 4$, to this chalk. However it is noted that disturbance from the rotary coring may have increased the aperture of the discontinuities, in which case an A4 or
B4 grading may more accurately reflect the in situ conditions. Below these depths, the quality of the core improved, with CIRIA chalk grades typically being in the $\mathrm{A} 2 / 3$ range.

A major feature of the chalk cores was the presence of steeply inclined (about $60-70^{\circ}$ dipping) joints, usually slickensided, polished and/or clay smeared. This style of fracturing was identified to be stratigraphically consistent within the Belle Tout Beds in all the TRC boreholes. 


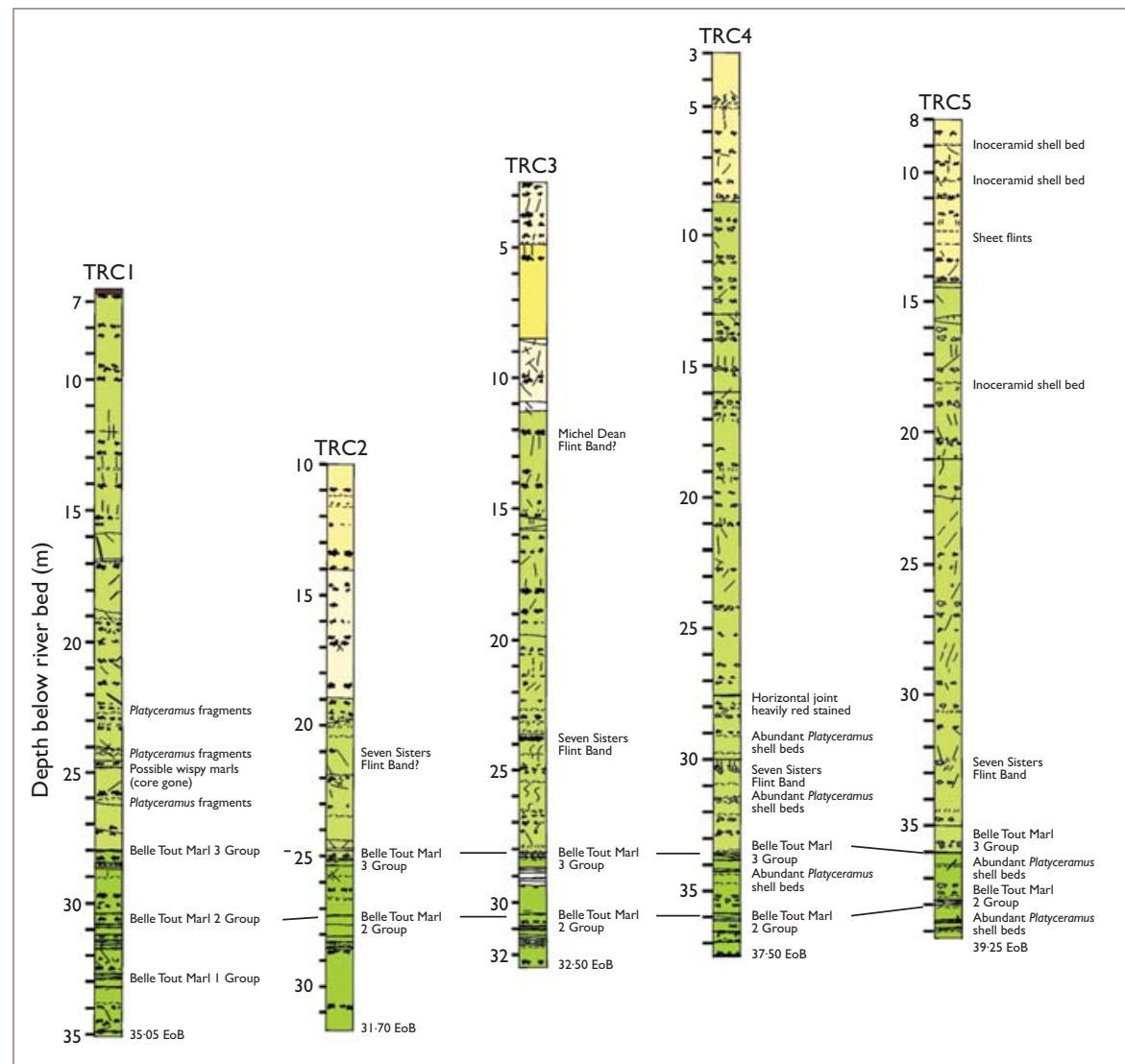

Fig. 13. Detailed stratigraphic logs for the chalk cores recovered from the boreholes with logs aligned at the top of Belle Tout Marl 3 Group

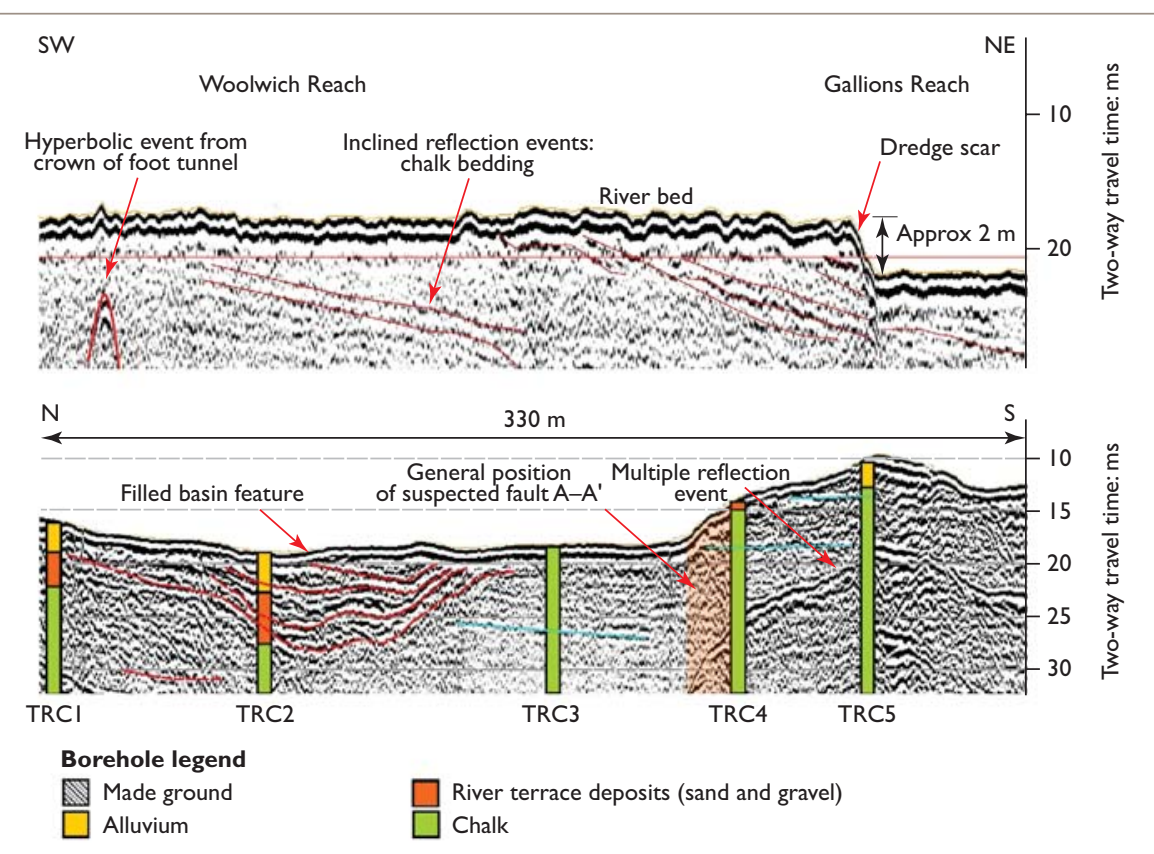

Fig. 14. Seismic boomer data acquired parallel to (top) and across river channel (bottom) together with logs from nearby boreholes. The survey revealed bedding planes and a filled-basin feature
Data from the down-hole geophysical tests provided additional information on the lithology and fracturing of the chalk, which was in general agreement with the detailed core logging. Presentation of results from the down-hole geophysical tests is beyond the scope of this paper.

Single-packer permeability tests were carried out in boreholes TRC2, TRC4 and TRC5. In borehole TRC3, a packer test was attempted and subsequently abandoned due to an inability to achieve an effective seal between the packer and the chalk. From the tests in boreholes TRC2 and TRC4, respective permeability values of $8 \times 10^{-6}$ and $4 \times 10^{-6} \mathrm{~m} / \mathrm{s}$ were calculated for the chalk in accordance with the recommendations given in BS5930: 1999. ${ }^{14}$ In borehole TRC5, a fracture in the chalk resulted in large head losses that prevented determination of an actual permeability, however the data are suggestive of a permeability in the order of $10^{-3} \mathrm{~m} / \mathrm{s}$.

When considered as a rock mass, chalk is a dual-porosity material. Intact chalk has small pores, which give it a relatively low permeability. Fractures passing through intact chalk provide more open horizons along which water can flow more readily and it is therefore the fractures which control mass permeability below the groundwater level. The lower permeabilities measured in TRC2 and TRC4 are in the range of those reported for the chalk matrix and/or fissured chalk, while the permeability suggested from the test in TRC5 is towards the upper range of that reported for fissured chalk. ${ }^{13}$

\section{Sub-bottom seismic survey results}

Seismic data quality was highest in the centre of the river channel. Example data are presented in Fig. 14. Correlation with borehole data indicates that extensive shallow-dipping reflection events visible in this section represent bedding surfaces within the chalk. These are present in good quality data throughout Woolwich Reach. The true dip of these beds has been calculated as around $2^{\circ} \mathrm{SE}$ to SSE.

Interpretation of seismic data also identified the presence of a probable backfilled feature in the chalk-head surface on the northern side of the riverbed. Correlation with the borehole logs for TRC1 and TRC2 confirmed the presence 
of this feature and identified the backfill material as being primarily alluvium and river terrace deposits.

The surface of the chalk bedrock was digitised by converting travel times into depths using seismic velocities calculated from correlation of seismic events with borehole data. ${ }^{8}$ The resultant data were gridded to form a three-dimensional digital elevation model for chalk bedrock head throughout Woolwich Reach, as shown in Fig. 15. The vertical resolution of this model is nominally $\pm 3 \mathrm{~m}$, with improved resolution obtained as the distance to the nearest borehole decreases. Note that data aquired in areas of shallow water are more difficult to interpret due to inhomogeneities in the surface sediments, likely to be caused by discarded rubbish, barge fenders and so on.

The three-dimensional presentation is useful for visualising the bedrock head geometry and can be used as input into design models requiring geological data. During interpretation, the minimum basal elevation and the approximate volume of the backfilled feature were determined to be $-20 \cdot 1 \pm 3 \mathrm{~m}$ OD and around $318000 \mathrm{~m}^{3}$, respectively.

\section{Discussion}

The site investigations in Woolwich Reach have identified several features that are important to the design and construction of the proposed Crossrail running tunnels, namely

current bathymetry of the riverbed

- distribution of ferrous material at, or close to, riverbed level

- position of faults within Woolwich Reach

- presence of a significant Quaternarysediment-filled basin feature cut into the chalk.

Knowledge of the current riverbed bathymetry has enabled the depth of cover above the running tunnels to be accurately determined and, when compared with historic bathymetric levels, provides insight into the bathymetric history of the riverbed. Woolwich Reach has been dredged in the past, however it is understood that no significant dredging is presently planned for this section of the River Thames.

\section{Unexploded bombs}

A magnetic gradiometer survey of the riverbed in this area has indicated the presence of scattered ferromagnetic objects at, or close to, riverbed level. Given the history of aerial bombardment in this area of London during the first and second world wars, there is a possibility that these metallic objects could correspond to UXO.

Historical accounts of air raids during World War II include accounts of bombs exploding in close proximity to the Woolwich Ferry. It is possible that debris from these attacks is present within the uppermost sediments of the riverbed. Although there is no definite identification of these metallic objects from the magnetic gradiometer survey, identified magnetic anomalies were avoided during the intrusive ground investigations.

The level of the Crossrail running tunnels is such they are expected to be beneath the ground penetration depth of any UXO. Similarly, the water intake structure for the former Woolwich Power Station identified toward the southern riverbank lies above the proposed tunnel alignment.

\section{Faults}

Stratigraphic interpretation of the chalk cores from boreholes TRC3 3 and TRC4 does not support the presence of the suspected vertical throwing east-west trending fault $\left(\mathrm{A}-\mathrm{A}^{\prime}\right)$ at the position shown in Fig. 4. This interpretation is supported by the seismic data which also show no evidence of a fault in this position. However, cores from TRC2 and TRC3 indicate that there is an offset in the marker beds of approximately $2 \mathrm{~m}$, down-throwing southwards. It is possible that this offset could be associated with an east-west trending fault, but at a more northerly position than previously suspected.

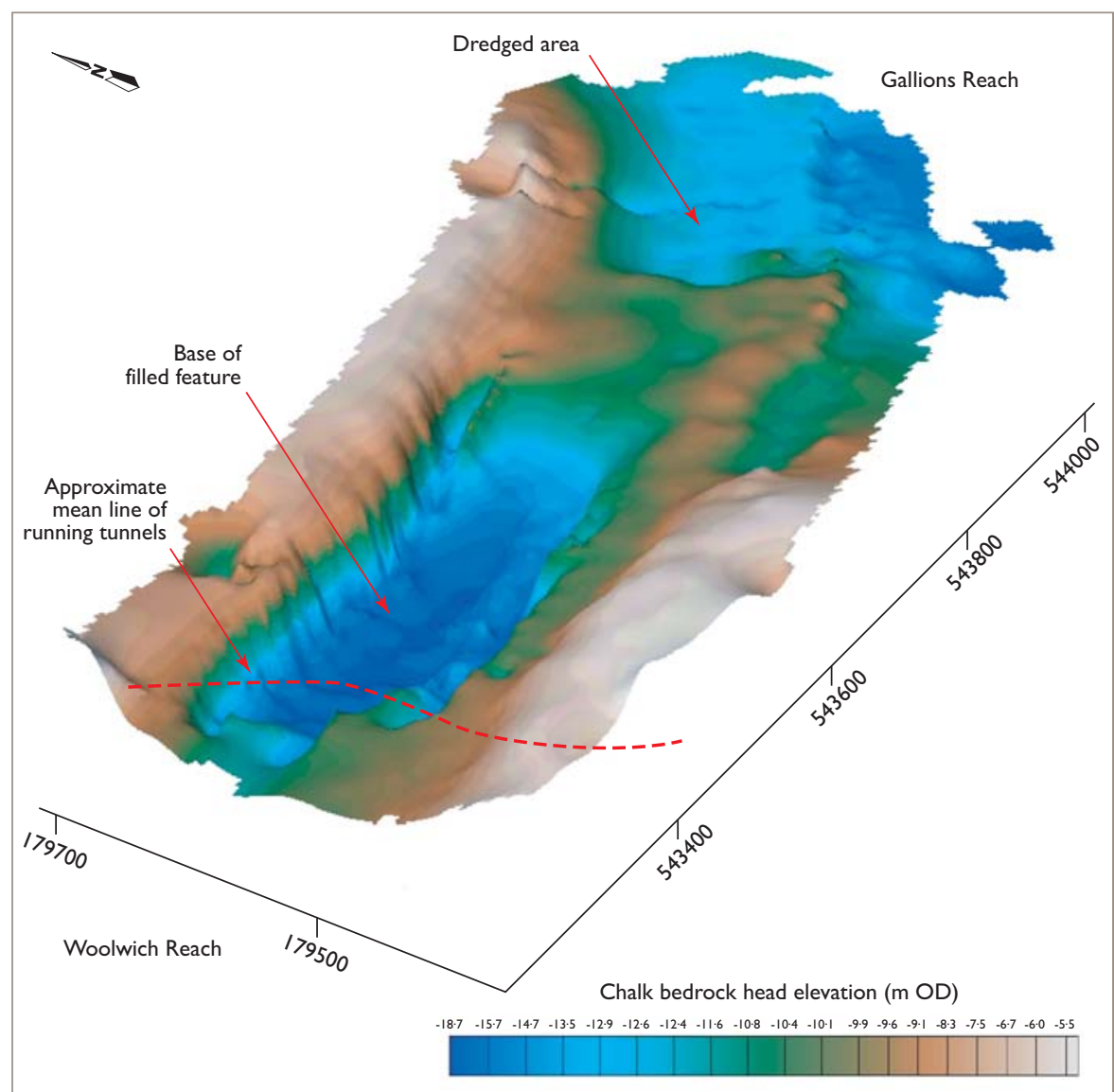

Fig. 15. Three-dimensional model of chalk bedrock under Woolwich and Gallions Reaches was constructed using interpreted seismic data and borehole records 
The most likely position for a fault between TRC 2 and TRC3 would be in the vicinity of the previously identified filledbasin feature, perhaps along its southern edge. However, the elevation difference in the marker beds could also be explained by a slight increase in the dip of the strata.

The boomer records suggest that there is a disturbance to the reflection pattern coincident with the suspected position of the northwest-southeast trending fault B-B' shown in Fig. 4. This fault was considered to be too distant from the proposed tunnel alignments to warrant further geotechnical investigation.

\section{Filled-basin feature}

The filled-basin feature identified in Woolwich Reach could have a number of man-made (artificial) and/or natural causes, including

man-made-dredging and aerial bombing during World War II

natural-scour/erosion, dissolution, glaciation.

Despite the history of dredging in Woolwich Reach, dredging is considered an unlikely origin of this feature since the feature is not adjacent to any known past or present structure (including the old ferry pier on the northern side of the river) and the chalk head elevation is irregular in comparison with other areas of the river that have been dredged (e.g. Gallions Reach).
Similarly, aerial bombardment during World War II is unlikely to have created this feature due to the size and/or number of high explosive bombs required to create a blast crater of this size.

Inspection of the three-dimensional presentation shown in Fig. 15 highlights that the filled-basin feature is a closed depression with a bowl-shaped cross-section and a roughly elliptical shape in plan view. This geometry is characteristic of a 'sinkhole' dissolution feature. ${ }^{10}$ Sinkholes normally occur at sites of increased discontinuity density where drainage is focused vertically through the rock. The seismic data is inconclusive with respect to discontinuity spacing underneath this basin feature. However, the cores from TRC2 down to approximately $-30 \mathrm{~m}$ OD were largely recovered as weak comminuted chalk. Similar cores were recovered from TRC1 down to approximately $-20 \mathrm{~m}$ OD. In contrast, structured chalk was recovered from the topmost cores (from -10 to $-12 \mathrm{~m}$ OD) in boreholes TRC3, TRC4 and TRC5, which suggests that the chalk underlying the filled-basin feature is of a lower quality and more highly fractured than the surrounding material. On this basis, the chalk cores provide supporting evidence for the sinkhole theory, perhaps with the postulated east-west trending fault acting to promote dissolution of the chalk in this area. Alluvial deposition within the developing surface depression would explain the stratigraphy encountered during the borehole investigations.

An alternative explanation for the natural origin of the filled-basin feature could be that the chalk was eroded by the action of the river. This mechanism would explain the upstream-downstream elongation of the feature, however it is unclear how a scour hollow of this size could have formed given that concurrent alluvial deposition would be expected. Scour is unlikely to be the primary origin of the filled-basin feature, though some erosion could have contributed to the present geometry.

A third possibility is a collapsed icepingo structure. This is suggested by the presence of comminuted-perhaps periglacially degraded—chalk. Dissolution processes tend to degrade chalk in a different way and the continuation of the comminuted chalk beyond the edges of the basin feature suggests the action of broader geological processes than localised dissolution. Ice-heave and collapse is common in the periglacially disturbed chalk and pingo-like structures are known in the Thames valley. ${ }^{12,15,16}$

Irrespective of its exact origin, the filled basin is important to the design and construction of the proposed Crossrail running tunnels. Fig. 16 presents a consolidated cross-section showing the riverbed bathymetry, borehole stratigraphy, the approximate boundary of the filled-basin feature and the proposed vertical alignment of the Crossrail running tunnels. From this figure it can be

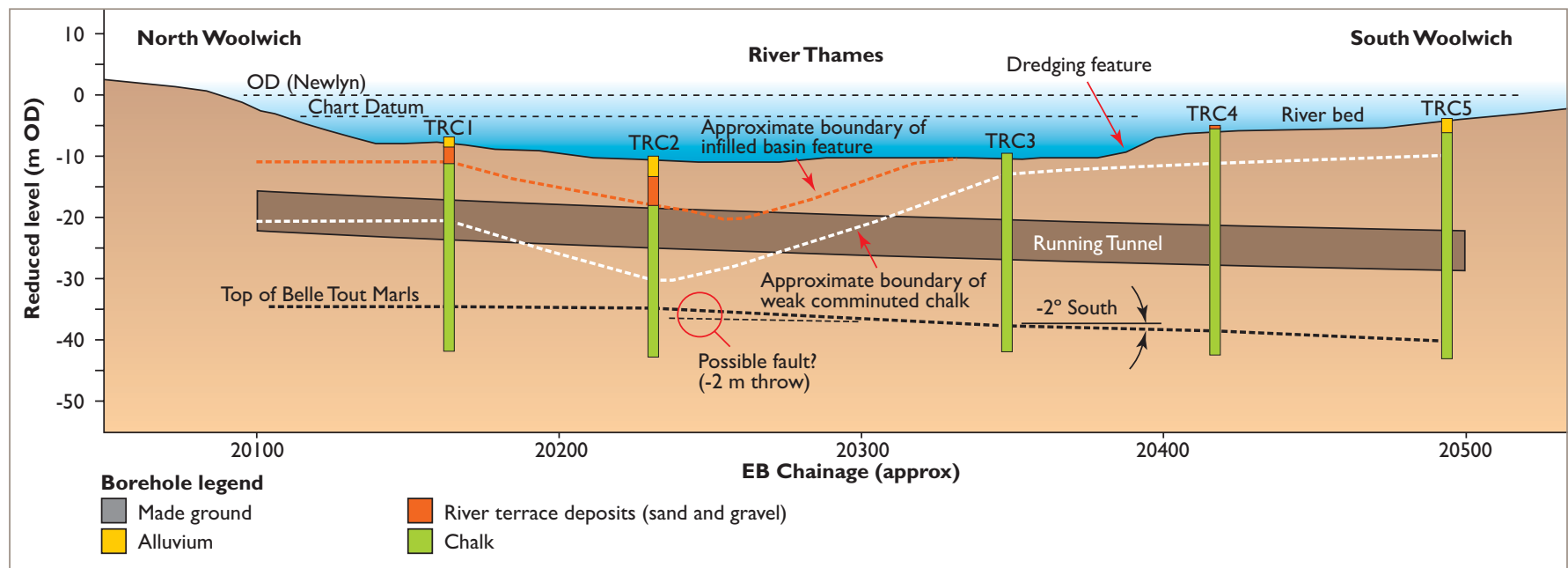


seen that, based on the present alignment, the running tunnels are anticipated to intersect the base of the basin feature. Following from this, two principal ground-related hazards to the Crossrail River Thames crossing have been identified:

high water inflows;

tunnel face instability.

Both of these hazards arise from the likelihood of encountering alluvial sediments (sands and gravels) and weak highly fractured chalk (both of which can be expected to be in direct hydraulic connectivity with the River Thames) within, or just above the tunnel horizon. These groundrelated hazards will need to be addressed in subsequent tunnel and tunnel-boring machine design.

\section{Conclusions}

A combined desk study, geophysical and intrusive geotechnical investigation has been undertaken in the River Thames for the proposed Crossrail Line 1 railway that is proposed to link east and west London. This investigation provided the following key information

identification of possible UXO locations

- determination of the nature and thickness of the ground cover over the tunnels

detailed stratigraphic logging of chalk core to identify key marker beds and flint bands

identification of a possible east-west trending fault of limited throw toward centre of river

discovery of a filled-basin feature of limited lateral and vertical extent

identification of weak, medium-density comminuted chalk within part of the tunnel horizon.

In so doing, a geological model for Woolwich Reach has been developed to assist with tunnel design and construction. The combination of geophysical and geotechnical investigation techniques employed in this project improved the continuity of along-alignment geological data available to the tunnel designer. Application of either investigative technique in isolation would have resulted in a far less complete geological model for the area.

Lessons learned from the variety of geophysical and geotechnical investigations carried out at this location included the following.

The importance of employing a range of sub-bottom profiling techniques where there is uncertainty in the ground conditions. In Woolwich Reach, data from the high-resolution boomer device proved to be of greatest use; very little information was gained from pinger sub-bottom profiling due to the acoustically reflective nature of the riverbed.

- The difficulty in recovering closely fractured weak chalk using rotary coring techniques. Associated disturbance of the recovered cores may result in the assignment of an engineering grading to the chalk that does not accurately

References

I. DEPARTMENT OF TRANSPORT, BRITISH RAIL NetWork SOUTH EAST, LONDON REGIONAL TRANSPORT and LONDON UNDERGROUND LTD. Central London Rail Study. Department of Transport, London, 1989.

2. Shadow Strategic Rall Authority. London East-West Study. SSRA, London, 2000.

3. BRITISH GEOLOGICAL SURVEY. Dartford (Solid and Drift Geology). Map No. E27I I:50000. BGS, Nottingham, 1988.

4. ELLISON R.A.,WOODS M.A.,ALLEN D. J., FORSTER A., PHAROAH T.C. and KING C. Geology of London-Special Memoir for 1:50000 Geological sheets E256 (North London), E257 (Romford), E270 (South London and E27I (Dartford) (England and Wales). BGS, Nottingham, 2004

5. PORT OF LONDON AUTHORITY HYDROGRAPHIC SERVICE. PLA Chart 324:Woolwich Reach (Lower) The United Kingdom Hydrographic Office, Taunton, 1999.

6. ANONYMOUS. The Woolwich footway tunnel. The Engineer, I November 1912,462-463.

7. ANONYMOUS. Woolwich footway tunnel opened. The Surveyor and Municipal and County Engineer, I November 1912, 42, 606-608.

8. FISH J.P. and CARR H.A. Sound Underwater Images - a Guide to the Generation and Interpretation of Side Scan Sonar. Lower Cape reflect the in situ conditions (such as that which would be determined from logging an exposure of the same material). Clues used to give CIRIA grades in these conditions included mineralstaining or fills on fracture surfaces.

- The difficulty in attaining an effective seal during packer permeability testing due to close fracture spacing and the presence of flints in the chalk.

\section{Acknowledgements}

The authors wish to acknowledge publication permission granted by Cross London Rail Links Ltd. The authors would also like to acknowledge the assistance provided by Docklands Light Railway Ltd, Transport for London, the Port of London Authority, the London Borough of Greenwich, Osiris Projects and Fugro Engineering Services Ltd.
Prleans, MA, 1988.

9. JONES E.J.W. Marine Geophysics. Wiley, Chichester, 1999.

10. REYNOLDS J. M. An Introduction to Applied and Environmental Geophysics. Wiley, Chichester, 1997.

II. MOSHER D.C. and SIMPKIN P. Status and trends of marine high-resolution seismic reflection profiling: data acquisition. Geoscience Canada, 1999, 26, No.4, I74-188

12. MORTIMORE R. M. Chalk Core Logging:The Thames River Crossing and Related Boreholes. Crossrail, London, 2004. Report No. IDOI0IE2G07-00502.

13. LORD J.A., Clayton C. R. I. and Mortimore R N. Engineering in Chalk. CIRIA, London, 2002. Report C574.

14. BRITISH StANDARDS INSTITUTION. British Standard Code of Practice for Ground Investigations. BSI, London, 1999. BS5930:1999.

I5. HAWKINS H. L.A pinnacle of chalk penetrating the Eocene on the floor of a buried river channel at Asford Hill, near Newbury, Berkshire. Quarterly Journal of the Geological Society, 1952, 108, No.3, 233-260.

16. Ballantyne C. K. and Harris C. The Periglaciation of Great Britain. Cambridge University Press, Cambridge, 1994, p.75 